ORIGINAL RESEARCH

\title{
Evaluation of Rock Climbing Related Injuries in Older Athletes
}

\author{
Christoph Lutter, $\mathrm{MD}^{1,2}$; Thilo Hotfiel, $\mathrm{MD}^{3,4}$; Thomas Tischer, $\mathrm{PhD}^{1}$; Robert Lenz, MD ${ }^{1}$; Volker Schöffl, $\mathrm{PhD}^{2,5,6}$ \\ ${ }^{1}$ Department of Orthopedics, University Medical Center, Rostock, Germany; ${ }^{2}$ Department of Sports Orthopedics, Sports Medicine, Sports Traumatology, \\ Klinikum Bamberg, Bamberg, Germany; ${ }^{3}$ Department of Orthopedics, Trauma and Hand Surgery, Klinikum Osnabrück, Osnabrück, Germany; ${ }^{4}$ Depart- \\ ment of Orthopedic Surgery, Friedrich-Alexander-University Erlangen-Nuremberg, Erlangen, Germany; ${ }^{5}$ Department of Trauma and Orthopedic Sur- \\ gery, Friedrich-Alexander-University Erlangen-Nuremberg, Erlangen, Germany; ${ }^{6}$ Department of Emergency Medicine, Section Wilderness Medicine, \\ University of Colorado School of Medicine, Denver, CO
}

Introduction-With the growing enthusiasm from people of all ages about rock climbing and bouldering, adaptions and medical conditions of the older athlete have become increasingly important. We aimed to analyze injury demographics, distribution, and severity for the older rockclimbing athlete.

Methods-During a 3-y period, we performed a single-center injury surveillance in athletes $\geq 35 \mathrm{y}$ of age presenting with rock climbing-related injuries or complaints. A standard questionnaire and examination protocol were conducted.

Results - A total of 198 patients (age 44.2 \pm 7.1 [35-77] y) (mean \pm SD, with range) with 275 independent injuries were recorded. Ninety percent of all injuries affected the upper extremity, $6 \%$ the lower extremity, and $4 \%$ other body regions. The Union Internationale des Associations d'Alpinisme injury scores were $2.0 \pm 0.3(1-4)$, and no fatalities occurred. Acute injuries were observed in $32 \%$ and overuse injuries in $68 \%$ of all injuries. Among the overuse injuries, $47 \%$ were classified as degenerative overuse conditions. Athlete age did not significantly correlate with the development of overuse injuries and UIAA injury score, but subgroup analysis showed a weak correlation of the climber age with the development of degenerative conditions $(P<0.05)$. The leading diagnosis of degenerative conditions was subacromial impingement syndrome of the shoulder.

Conclusions-Compared to younger athletes, older rock climbers demonstrate a higher proportion of overuse injuries, especially degenerative conditions. Profound knowledge of climbing injuries patterns and conditions in older rock climbers is crucial to prevent injuries among all age groups and to decrease the number of degenerative injuries.

Keywords: masters athlete, senior athlete, veteran athlete, bouldering, injury surveillance

\section{Introduction}

Physical activity has been established as one of the most influential factors in healthy old age. Although many populations experience obesity, immobilization, and improper nutritional behavior, many older adults - some even in the

Corresponding author: Christoph Lutter, MD, Department of Sports Orthopedics, Sports Medicine, Sports Traumatology Klinikum Bamberg, Bamberg 96049, Germany.; e-mail: christoph.lutter@med.uni-rostock.de. Submitted for publication February 2019.

Accepted for publication June 2019. higher age ranges of the population-are very active in sports. A sport that is well known to engage athletes on a life-long basis is rock climbing, which was recently announced as part of the next 2020 Summer Olympic Games in Tokyo. This landmark decision reflects rising worldwide interest in and enthusiasm for a sport that has proven to have health-promoting effects and an overall low injury risk. ${ }^{1-4}$ However, modern climbing and training methods have changed, and a wider spectrum of climbingrelated injuries can be detected currently. ${ }^{5}$ Several studies on climbing injuries have been conducted in the past, focusing on injury grading and incidence and on diagnostic 
and treatment strategies. ${ }^{6}$ However, injury surveillance studies for rock climbing injuries are still rare, and none have been performed for older athletes. ${ }^{7}$ Furthermore, the rapid increase in today's generation of climbers aged 20 to $30 \mathrm{y}$ will likely lead to a wave of elder athletes in the future.

Available studies underline the fact that the incidence of overall climbing injury is minor and that most injuries are of a minor grade. ${ }^{2,6}$ Acute injuries in climbing are related to a fall onto the lower leg or from performing a difficult move and injuring the upper extremity. ${ }^{3,8}$ Beyond this, overuse injuries can result from permanent undue stress and overload, mainly of the upper extremity. Most climbing-related scientific studies tend to focus on sport-specific injuries, such as flexor tendon pulley injuries, because these injuries occur the most frequently. ${ }^{6,9}$ Expecting a rising number of very active older rock-climbing athletes due to the increase in popularity of climbing and bouldering, it is important to further analyze this patient population. ${ }^{8}$ The objective of this study was to examine injury demographics, distribution, and severity in older rock-climbing athletes.

\section{Methods}

The study was approved by the institutional review board (University of Erlangen-Nuremberg), and all patients provided informed consent.

\section{DATA ACQUISITION}

Between 2016 and 2018, all patients aged $\geq 35$ y who presented at our clinic for acute or overuse injuries caused by rock climbing or bouldering were assessed (Table 1). Sports injuries caused by rock climbing or bouldering activities were defined as medical conditions forcing the athlete to rest from the sport because of pain or dysfunction and causing the need to seek help from a physician.

Acute injuries were defined as injuries with a sudden onset during climbing without any history of symptoms, and overuse injuries were defined as chronic injuries without a singular causing event or specific trauma that developed during or after climbing. Among overuse injuries, degenerative conditions were defined as nonreversible injuries that worsened over time.

All patients were seen and treated in our specialized outpatient sports medicine clinic, which is a referral center for climbing-related injuries (eg, German Alpine Club). Imaging techniques such as radiographs, magnetic resonance imaging, or ultrasound were performed following current guidelines. ${ }^{10}$ Diagnoses were made based on clinical investigation and radiologic findings by 2 experienced orthopedic surgeons (CL, VS) in the field of climbing-related injuries. All final diagnoses were reviewed and confirmed by the senior author (VS), who has $>20 \mathrm{y}$ of related clinical experience. Patients with acute injuries who were initially seen and treated in the emergency department of our 24-h level 1 trauma center were later re-examined in the outpatient sports medicine clinic. The clinic is 1 of 3 trauma centers in Germany's biggest and most popular outdoor sport-climbing and bouldering area, the Frankenjura (Bavaria, Germany).

A standard questionnaire, including questions for preexisting medical conditions, medical history, and an examination protocol, was used for all patients. Only patients experiencing pain during or after climbing were included in the study. The Union Internationale des Associations d'Alpinisme (UIAA) metric scale was used for evaluation of climbing levels, as previously published. ${ }^{2,11}$ The orchard sports injury classification system 10 (OSICS 10) scale was used to categorize the injury distribution following the UIAA MedCom recommendation. ${ }^{11}$ Subgroup analyses

Table 1. Patient demographics

\begin{tabular}{|c|c|c|c|c|c|}
\hline & \multirow[b]{2}{*}{ All patients } & \multicolumn{3}{|c|}{ Age (y) } & \multirow[b]{2}{*}{$\mathrm{P}$ value } \\
\hline & & $35-49$ & $50-64$ & $\geq 65$ & \\
\hline No. of patients & 198 & 146 & 48 & 4 & - \\
\hline No. of injuries & 275 & 217 & 54 & 4 & - \\
\hline Age $(y)$ & $44 \pm 7(35-77)$ & $41 \pm 4(35-49)$ & $53 \pm 3(50-62)$ & $72 \pm 5(65-77)$ & - \\
\hline Sex (men-women) & $150-48$ & $104-42$ & $42-6$ & $4-0$ & - \\
\hline Height (cm) & $175 \pm 9(157-194)$ & $174 \pm 9(157-194)$ & $178 \pm 9(158-193)$ & $172 \pm 4.6(168-178)$ & - \\
\hline Weight (kg) & $68.7 \pm 9.5(47-90)$ & $67.6 \pm 9.4(47-90)$ & $71.9 \pm 9.4(51-85)$ & $67.3 \pm 5.9(61-74)$ & - \\
\hline Climbing h/wk & $6.6 \pm 4.9(0-20)$ & $6.7 \pm 5.4(0-20)$ & $6.6 \pm 4.1(0-15)$ & $1.8 \pm 1(1-3)$ & 0.104 \\
\hline UIAA level & $8.7 \pm 1.2(4.3-11.3)$ & $8.9 \pm 1.2(4.3-11.3)$ & $8.3 \pm 1(6.5-10.0)$ & $7.1 \pm 0.2(7.0-7.3)$ & $<0.001$ \\
\hline Climbing years & $19.8 \pm 11.2(1-64)$ & $17.8 \pm 9.5(1-38)$ & $24.4 \pm 11.6(5-47)$ & $53.5 \pm 7.0(50-64)$ & $<0.001$ \\
\hline Bouldering (\%) & $44.5 \pm 36.6(0-100)$ & $45.9 \pm 38.2(0-100)$ & $41.6 \pm 34.2(0-100)$ & 0 & \\
\hline
\end{tabular}

UIAA, Union Internationale des Associations d'Alpinisme. 
were made for 3 age groups: $35-50,50-65$ and $>65$ y of age. For further specification of groups, correlation analysis and multiple comparisons were performed. Age groups were defined based on the available literature on master athletics. ${ }^{4,12-14}$

\section{STATISTICAL ANALYSIS}

Microsoft Excel (Microsoft, Redmond, WA) was used for data collection; statistical analyses were performed using SigmaStat software (Systat Software Inc., San Jose, CA). Values were checked for normality with the Shapiro-Wilk test. To determine the difference between groups, a t test or rank-sum test was used, depending on normal distribution. A nonparametric Kruskal-Wallis 1-way analysis of variance on ranks was used for nonnormally distributed data among several groups. It was determined whether there was a correlation between the occurrence of different injury types (acute or overuse injury). For further specification of groups, correlation analysis and multiple comparisons were performed. The Pearson $r$ or Spearman $r$ coefficient was adopted as a mathematical measure of correlation strength, depending on normal distribution. Cramer $\mathrm{V}$ was calculated in cases of nominally scaled data. Data are expressed as mean \pm SD with range. Subgroup analyses were made for 3 age groups as described. $P$ values $<0.05$ were considered statistically significant.

\section{Results}

During the 3-y period, we treated 198 patients aged $\geq 35 \mathrm{y}$ (150 [76\%] male, 48 [24\%] female) with a total number of 275 independent injuries caused by rock climbing or bouldering (Table 1). Among these, 57 patients had 2 different injuries during the study period, and 10 patients had 3 different diagnoses. Among the 275 injuries, 187 (68\%) were overuse injuries and 88 (32\%) were acute injuries. The percentage of bouldering in the climbing routine and training was described by the athletes as $44.5 \pm 6.6 \%$ $(0-100 \%)$. None of the athletes in the $>65 \mathrm{y}$ age group reported partaking in bouldering on a regular basis. Table 2 provides a comparison of the injury distribution, injury grades and injury types presented as previously published. The localization and classification of injuries following the OSICS 10 score are presented in Tables 3 and 4, respectively. ${ }^{11}$

Representing $15 \%$ of all injuries, a finger pulley laceration (single or multiple pulley rupture) was the most frequent diagnosis, followed by finger joint capsulitis (12\%), subacromial impingement (10\%), and finger tenosynovitis (7\%; Table 5). Among degenerative conditions, subacromial impingement syndrome was the most frequent diagnosis $(32 \%)$, followed by chronic superior labral tear from anterior to posterior lesions (22\%), osteoarthritis of the fingers (14\%), and Dupuytren disease (10\%; Table 6).

UIAA injury scores were $2.0 \pm 0.3(1-4)$. Among the 7 injured athletes with a UIAA score of $\geq 3$; there was only 1 female athlete. All of the athletes in this group had experienced joint displacements or joint fractures after a fall. None of the athletes had a UIAA grade 5 injury, and none died (UIAA 6). Climbing level (UIAA level, $P<0.001$ ) and climbing experience (climbing years, $P<0.001$ ) were both significantly higher in men than in women. Among the entire study population, athlete age did not significantly correlate with the development of overuse or acute injuries and the UIAA injury score. Subgroup analysis of overuse injuries showed a weak correlation between climber age and the development of a degenerative condition (Tables 5 and 6). The $>65$ y age group did not show a significant difference because of the small sample size. No significant association between the climber's UIAA climbing level, climbing hours per week, years of climbing, height, weight, and sex and the development of an acute or overuse injury was found. The UIAA injury score was also not significantly influenced by any of these individual parameters.

Athletes affected by acute injuries did not have significantly higher UIAA scores than those affected by overuse injuries.

\section{Discussion}

To implement an injury prevention sequence as described earlier, an investigation of the extent and dynamics of injuries associated with rock climbing in older athletes is a crucial first step. ${ }^{7,15,16}$ Although several studies on climbing injuries in larger patient collectives or adolescent climbers have been published so far, none of the available literature has focused on the distribution and degree of injuries in the older athlete. ${ }^{1,2,9}$ Three studies reported a mean age for injured climbers of $26(2-74) \mathrm{y}, 28 \pm 12(13-52) \mathrm{y}$, and $34 \pm 11$ (11-77) y, respectively. ${ }^{2,3,9}$ Patients in our study had a significantly higher mean age of $44 \pm 7$ (35-77) y, but climbing levels (UIAA $8.7 \pm 1.2$ ) were comparable to those in previously published data. ${ }^{2,3,9}$ With a ratio of $3: 1$, we observed a significantly higher rate of injured male climbers than female climbers. Climbing levels and climbing experience were both significantly higher in males. Thus, sex did not influence the severity of injury. These findings are in accordance with most other available data. ${ }^{2,3,9}$ Contrary to findings of 2 previously published studies, we could not confirm a correlation between climbing difficulty (UIAA score) and the development of overuse injuries. ${ }^{2,3}$ Furthermore, neither UIAA climbing level nor the climber's experience (years of climbing) significantly influenced the development of 
Table 2. Patient injury distribution, grading, and type

\begin{tabular}{lllll}
\hline Patients $(n=198)$ & $\begin{array}{l}\text { All }(n=275) \\
n(\%)\end{array}$ & $\begin{array}{l}\text { Age 35-49y }(n=217) \\
n(\%)\end{array}$ & $\begin{array}{l}\text { Age 50-64 y }(n=54) \\
n(\%)\end{array}$ & $\begin{array}{l}\text { Age } \geq 65 y(n=4) \\
n(\%)\end{array}$ \\
\hline $\begin{array}{l}\text { Injury distribution } \\
\text { Upper extremity }\end{array}$ & $246(90)$ & $196(90)$ & $48(90)$ & $2(50)$ \\
Lower extremity & $19(6)$ & $15(6)$ & $3(5)$ & $1(25)$ \\
Other & $10(4)$ & $6(4)$ & $3(5)$ & - \\
Injury grading & $12(4)$ & $11(5)$ & 1 & $4(100)$ \\
UIAA 1 & $256(93)$ & $201(93)$ & $51(94)$ & - \\
UIAA 2 & $6(2)$ & $4(2)$ & $2(4)$ & - \\
UIAA 3 & 1 & 1 & - & - \\
UIAA 4 & - & - & $21(39)$ & $0(0)$ \\
UIAA 5-6 & $88(32)$ & $69(32)$ & $35(61)$ & $4(100)$ \\
Injury type & $187(68)$ & $148(68)$ & $24 / 35(69)$ & $1 / 4(25)$ \\
Acute & $88 / 187(47)$ & $63 / 148(43)$ & & \\
Overuse & & & \\
Degenerative conditions & & & \\
\hline
\end{tabular}

UIAA, Union Internationale des Associations d'Alpinisme.

an overuse injury. This finding is remarkable because one would most expect overuse injuries in very old athletes with decades of climbing history. However, this might result from the small subgroup of athletes $>65 \mathrm{y}$ old in our data set or could be due to a selection bias that only allowed athletes who were low- or intermediate-level climbers in their younger ages to continue their climbing career at older ages. However, our questionnaire did not provide specific details on the prior climbing routine in an athlete's history. It is important to note that among the group of overuse injuries, nonreversible degenerative conditions were found in $69 \%$ of athletes aged $50-64 \mathrm{y}$, whereas only $42 \%$ of younger climbers (35-49 y) were affected. The overall higher prevalence of various conditions such as subacromial impingement syndrome in older patients may also be a contributing factor. ${ }^{17}$
As reported in investigations of younger rock-climbing athletes, the vast majority of injuries (90\%) affected the upper extremity in our study. ${ }^{1,6,9}$ In a prospective analysis of more than half a million entries to an indoor climbing and bouldering gym, the authors found an injury rate of $0.02 / 1000 \mathrm{~h}$, of which only 15 were of UIAA injury scale grade 2, 13 UIAA 3, and 2 UIAA $4 .{ }^{18}$ No higher graded injuries (UIAA injury scale) were reported, and no fatalities occurred in the study. The severity of injuries in our study was also mostly low, with a UIAA score of 2 (defined as moderate severe injury) in 93\% of all cases. ${ }^{11}$ Only 6 acute cases were classified as UIAA grade 3 injuries, and 1 polytraumatic patient was classified as a grade 4 injury. This is remarkable, considering our hospital is one of the major trauma centers of Germany's biggest and most popular outdoor climbing areas, the Frankenjura. This overall minor grade of injury severity is mostly in accordance

Table 3. Injury distribution according to body area

\begin{tabular}{lllll}
\hline Body area $(n=198)^{a}$ & $\begin{array}{l}\text { All }(n=275) \\
n(\%)\end{array}$ & $\begin{array}{l}\text { Age 35-49y }(n=217) \\
n(\%)\end{array}$ & $\begin{array}{l}\text { Age 50-64 y }(n=54) \\
n(\%)\end{array}$ & $\begin{array}{l}\text { Age } \geq 65 y(n=4) \\
n(\%)\end{array}$ \\
\hline Finger & $135(49)$ & $112(52)$ & $22(41)$ & $1(25)$ \\
Shoulder & $63(23)$ & $46(20)$ & $16(29)$ & - \\
Hand & $24(8)$ & $20(9)$ & $4(7)$ & - \\
Forearm and elbow & $28(10)$ & $21(9)$ & $7(13)$ & - \\
Lower leg and foot & $13(4)$ & $11(5)$ & $2(3)$ & - \\
Knee & $3(1)$ & $3(1)$ & $2(3)$ & $1(25)$ \\
Trunk and spine & $6(2)$ & $3(1)$ & 1 & - \\
Pelvis & $3(1)$ & 1 & - & - \\
Other & - & - & & - \\
\hline
\end{tabular}

${ }^{a}$ Anatomic locations are specified as previously published. 
Table 4. Injury distribution of anatomical sites according to the OSICS

\begin{tabular}{|c|c|c|c|c|c|c|}
\hline Main grouping & Category & $\begin{array}{l}\text { OSCIS } \\
\text { designation }\end{array}$ & $\begin{array}{l}A l l \\
(n=275) \\
n(\%)\end{array}$ & $\begin{array}{l}\text { Age } 35-49 y \\
(n=217) \\
n(\%)\end{array}$ & $\begin{array}{l}\text { Age } 50-64 \text { y } \\
(n=54) \\
n(\%)\end{array}$ & $\begin{array}{l}\text { Age } \geq 65 y \\
(n=4) \\
n(\%)\end{array}$ \\
\hline \multirow[t]{2}{*}{ Head and neck } & Head/Face & $\mathrm{H}$ & - & - & - & - \\
\hline & Neck/Cervical spine & $\mathrm{N}$ & $2(1)$ & - & $1(2)$ & $1(25)$ \\
\hline \multirow[t]{6}{*}{ Upper limbs } & Shoulder/Clavicle & $\mathrm{S}$ & $59(21)$ & $45(20)$ & $14(26)$ & - \\
\hline & Upper arm & $\mathrm{U}$ & $3(1)$ & 1 & $2(4)$ & - \\
\hline & Elbow & $\mathrm{E}$ & $25(9)$ & $18(8)$ & $7(13)$ & - \\
\hline & Forearm & $\mathrm{R}$ & $2(1)$ & $2(1)$ & - & - \\
\hline & Wrist & $\mathrm{W}$ & $12(4)$ & $11(5)$ & $1(2)$ & - \\
\hline & Hand/Finger/Thumb & $\mathrm{P}$ & $145(53)$ & $119(55)$ & $24(44)$ & $2(50)$ \\
\hline \multirow[t]{5}{*}{ Trunk } & Chest (sternum/ribs) & $\mathrm{C}$ & - & - & - & - \\
\hline & Thoracic spine & $\mathrm{D}$ & - & - & - & - \\
\hline & Abdomen & $\mathrm{O}$ & - & - & - & - \\
\hline & Lumbar spine & $\mathrm{B}$ & - & - & - & - \\
\hline & Pelvis and buttock & $\mathrm{L}$ & $3(1)$ & $2(1)$ & $1(2)$ & - \\
\hline \multirow[t]{6}{*}{ Lower limbs } & Hip/Groin & $\mathrm{G}$ & $3(1)$ & 1 & $1(2)$ & $1(25)$ \\
\hline & Thigh & $\mathrm{T}$ & - & - & - & - \\
\hline & Knee & $\mathrm{K}$ & $3(1)$ & $3(1)$ & - & - \\
\hline & Lower leg & Q & $2(1)$ & 1 & $1(2)$ & - \\
\hline & Ankle & A & $5(2)$ & $5(2)$ & - & - \\
\hline & Foot/Toe & $\mathrm{F}$ & $6(2)$ & $5(2)$ & $1(2)$ & - \\
\hline Location unspecified & & $\mathrm{X}$ & $5(2)$ & $4(2)$ & $1(2)$ & - \\
\hline
\end{tabular}

OSCIS, orchard sports injury classification system 10 .

with the previously published data. It is notable that we do see a slight increase of more severe injuries, graded UIAA 3 and higher, compared to prior studies on younger athletes., ${ }^{2,3}$ Contrary to expectations that more severe injuries would be more probable in younger, more aggressive, and occasionally reckless athletes, our study might confirm the recent trend in which we have seen an overall shift to more serious injuries during the past $5 \mathrm{y} .{ }^{5}$ This finding is most likely caused by indoor bouldering and the rising number of people being enthusiastic about this sport. ${ }^{5}$
Among the 10 most frequent injuries in the older rockclimbing athlete, subacromial impingement syndrome (Table $5 ; 10 \%$ of all patients) was found to occur twice as frequently in this population compared to younger athletes in the existing literature. ${ }^{2}$ This is most likely influenced by the overall higher prevalence of impingement syndrome in older patients. ${ }^{17}$ Osteoarthritis of the finger was present in $4 \%$ of our athletes. This condition had previously been described to represent only $3 \%$ of all finger injuries in younger rock climbers. ${ }^{2}$ Our findings are in agreement

Table 5. Ten most frequent injuries in the older rock-climbing athlete

\begin{tabular}{lllll}
\hline Injuries & $\begin{array}{l}A l l(n=275) \\
n(\%)\end{array}$ & $\begin{array}{l}\text { Age 35-49y }(n=217) \\
n(\%)\end{array}$ & $\begin{array}{l}\text { Age 50-64 y }(n=54) \\
n(\%)\end{array}$ & $\begin{array}{l}\text { Age } \geq 65 y(n=4) \\
n(\%)\end{array}$ \\
\hline Pulley injury & $41(15)$ & $33(15)$ & $8(15)$ & - \\
Capsulitis (finger) & $34(12)$ & $27(12)$ & $6(11)$ & $1(25)$ \\
Impingement (shoulder) & $28(10)$ & $19(8)$ & $8(15)$ & - \\
Tenosynovitis & $20(7)$ & $19(8)$ & $1(2)$ & - \\
SLAP tear & $19(6)$ & $17(7)$ & $2(4)$ & - \\
Epicondylitis & $15(6)$ & $13(5)$ & $4(7)$ & - \\
Osteoarthritis (finger) & $12(4)$ & $8(4)$ & $3(6)$ & - \\
Dupuytren disease & $9(3)$ & $6(3)$ & $1(2)$ & - \\
Strain finger joint capsule & $9(3)$ & $8(4)$ & $1(2)$ & \\
Strain finger flexor tendon & $8(3)$ & $7(3)$ & & \\
\hline
\end{tabular}

SLAP, superior labral tear from anterior to posterior. 
Table 6. Most frequent degenerative conditions in the older rock-climbing athlete

\begin{tabular}{lllll}
\hline Injuries & $\begin{array}{l}\text { All }(n=88 \\
\text { degenerative } \\
\text { injuries })\end{array}$ & $\begin{array}{l}\text { Age 35-49 } y(n=63 \\
\text { degenerative } \\
\text { injuries }) \\
n(\%)\end{array}$ & $\begin{array}{l}\text { Age 50-64 } y(n=24 \\
\text { degenerative } \\
\text { injuries }) \\
n(\%)\end{array}$ & $\begin{array}{l}\text { Age } \geq 65 y(n=1 \\
\text { degenerative } \\
\text { injury }) \\
n(\%)\end{array}$ \\
\hline Impingement (shoulder) & $28(32)$ & $19(29)$ & $8(33)$ & 1 \\
SLAP tear & $19(22)$ & $17(27)$ & $2(8)$ & - \\
Osteoarthritis (finger) & $12(14)$ & $8(13)$ & $4(17)$ & - \\
Dupuytren disease & $9(10)$ & $6(10)$ & $3(13)$ & - \\
Biceps tendon rupture (LBT) & $6(7)$ & $4(9)$ & $3(13)$ & - \\
Osteoarthritis elbow & $6(7)$ & $3(5)$ & - & - \\
Osteoarthritis foot & $4(5)$ & $4(6)$ & $2(8)$ & - \\
Other & $4(5)$ & $2(3)$ & & \\
\hline
\end{tabular}

LBT, long biceps tendon; SLAP, superior labral tear from anterior to posterior.

with a recently published study on long-term radiographic adaptations of the fingers to the stress of high-level and recreational rock climbing. ${ }^{19}$ Osteoarthritis of the fingers represented the seventh leading cause of complaints in the older rock climber (Table 5).

\section{STUDY LIMITATIONS}

This study had several limitations. The patient collective was not fully homogenous; most of the athletes came from the local climbing area, but a few were from further away. The kind of climbing performed in certain areas might influence the type of injuries. Furthermore, the questionnaire did not include specific questions on the exact cause of injury or environmental conditions or circumstances. Because we are very active in treating injuries of the upper extremity, there is a patient selection bias. Nevertheless, this bias exists in all of our studies and is therefore somewhat consistent. The main limitation might be the small sample size and the inconsistent number of patients among the groups, with only 4 athletes in the group $>65 \mathrm{y}$ of age.

\section{Conclusions}

This study contributes to a wider understanding within the investigated field of injury demographics, distribution, and severity in older rock-climbing athletes and therefore could be the first step in an injury prevention sequence in older athletes. ${ }^{15,16}$ Although the injury distribution overall is comparable to that in younger athletes, degenerative conditions such as impingement syndrome of the shoulder or osteoarthritis of the fingers are common injuries in older athletes. We therefore recommend a careful, sports-specific medical supervision and evidence-based education under consideration of age-specific factors to prevent injuries among all age groups and to decrease the number of degenerative injuries in older rock climbers. Further analysis and evaluation of athletes, especially in the age groups $>50 \mathrm{y}$, are necessary.
Acknowledgments: The authors thank Rosamunde Pare for English language support.

Author Contributions: Study design (CL, TH, and VS). Monitoring of data collection and analyzation (CL, TH, TT, RL, and VS). Interpretation of data (CL, TH, TT, RL, and VS). Drafting and final approval of the manuscript (CL, TH, TT, RL, and VS).

Financial/Material Support: None.

Disclosure: None.

\section{References}

1. Neuhof A, Hennig FF, Schoffl I, Schoffl V. Injury risk evaluation in sport climbing. Int J Sports Med. 2011;32(10): 794-800.

2. Schoffl V, Popp D, Kupper T, Schoffl I. Injury trends in rock climbers: evaluation of a case series of 911 injuries between 2009 and 2012. Wilderness Environ Med. 2015;26(1):62-67.

3. Schoffl V, Hochholzer T, Winkelmann HP, Strecker W. Pulley injuries in rock climbers. Wilderness Environ Med. 2003;14(2):94-100.

4. Dores H, de Araujo Goncalves P, Monge J, Costa R, Tátá L, Malhotra A, et al. Subclinical coronary artery disease in veteran athletes: is a new preparticipation methodology required? Br J Sports Med. 2018 [Epub ahead of print].

5. Schoffl V, Lutter C. The "newbie" syndrome. Wilderness Environ Med. 2017;28(4):377-380.

6. Woollings KY, McKay CD, Emery CA. Risk factors for injury in sport climbing and bouldering: a systematic review of the literature. Br J Sports Med. 2015;49(17):1094-1099.

7. van Mechelen W, Hlobil H, Kemper HC. Incidence, severity, aetiology and prevention of sports injuries. A review of concepts. Sports Med. 1992;14(2):82-99.

8. Lutter C, El-Sheikh Y, Schoffl I, Schoffl V. Sport climbing: medical considerations for this new Olympic discipline. Br J Sports Med. 2017;51(1):2-3.

9. Nelson NG, McKenzie LB. Rock climbing injuries treated in emergency departments in the US, 1990-2007. Am J Prev Med. 2009;37(3):195-200.

10. Kramer KL, Jani L, Grifka J, Scharf HP, Schleberger R, Zacher J. Guidelines in orthopaedic surgery. A first step. Orthopade. 1999;28(3):236-242. 
11. Schöffl V, Morrison A, Hefti U, Ullrich S, Kupper T. The UIAA medical commission injury classification for mountaineering and climbing sports. Wilderness Environ Med. 2011;22(1):46-51.

12. Soto-Quijano DA. The competitive senior athlete. Phys Med Rehabil Clin N Am. 2017;28(4):767-776.

13. Medic N, Lares J, Young BW. The constituent year effect: relative age disparities in Australian masters track and field athletic participation. Sports (Basel). 2018;6(4).

14. Chugh SS, Weiss JB. Sudden cardiac death in the older athlete. J Am Coll Cardiol. 2015;65(5):493-502.

15. van Mechelen W. Sports injury surveillance systems. 'One size fits all'? Sports Med. 1997;24(3):164-168.

16. Van Tiggelen D, Wickes S, Stevens V, Roosen P, Witvrouw E. Effective prevention of sports injuries: a model integrating efficacy, efficiency, compliance and risk-taking behaviour. $\mathrm{Br} J$ Sports Med. 2008;42(8): 648-652.

17. Garving C, Jakob S, Bauer I, Nadjar R, Brunner UH. Impingement syndrome of the shoulder. Dtsch Arztebl Int. 2017;114(45):765-776.

18. Schoffl VR, Hoffmann G, Kupper T. Acute injury risk and severity in indoor climbing-a prospective analysis of 515,337 indoor climbing wall visits in 5 years. Wilderness Environ Med. 2013;24:187-194.

19. Schoffl VR, Hoffmann PM, Imhoff A, et al. Long-term radiographic adaptations to stress of high-level and recreational rock climbing in former adolescent athletes: an 11-year prospective longitudinal study. Orthop J Sports Med. 2018;6(9), 2325967118792847. 